\title{
Estudo de 15 casos de piedra branca observados na Grande Vitória (Espírito Santo - Brasil) durante cinco anos"
}

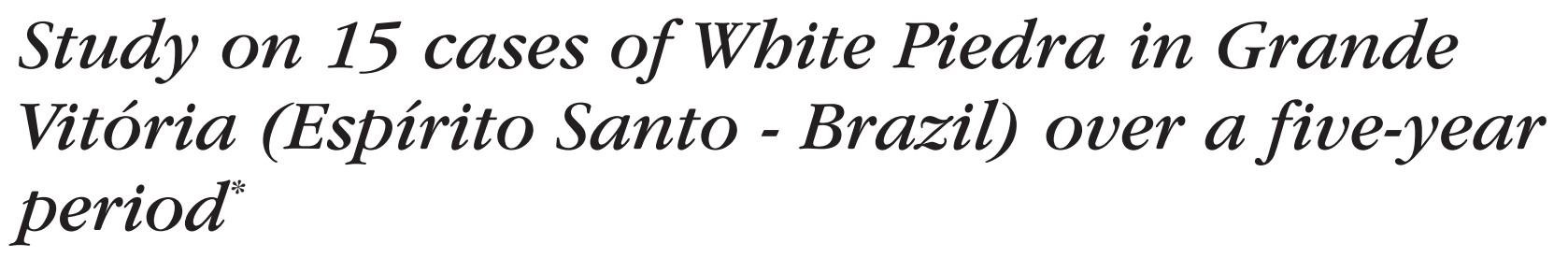

Lucia Martins Diniz ${ }^{1}$

João Basilio de Souza Filho

Resumo: A piedra branca é infecção fúngica do pêlo, rara, causada pelo Trichosporon beigelii, caracterizada por nódulos amarelados nos pêlos genitais, bigode, barba, axilas e raramente, no couro cabeludo. O estudo registra 15 casos, diagnosticados em serviço de dermatologia de Vitória, durante cinco anos, todos de pacientes do sexo feminino, com nódulos nos pêlos do couro cabeludo. Os autores supõem que o clima quente e úmido da região e o hábito de as pacientes utilizarem cremes recondicionadores nos fios dos cabelos tenham favorecido a infecção. O umedecimento dos fios com água facilita a visualização dos nódulos. Palavras-chave: Micoses; Piedra; Trichosporon.

\begin{abstract}
White Piedra is a rare fungal infection of the hair shaft, caused by a yeast-like fungus (Trichosporon beigelii), characterized by yellow nodules on the pubic hair, moustache, beard and hair on the axillae and scalp. The objective was to register the presence of 15 cases of White Piedra in Espirito Santo diagnosed at the Dermatology Service in Vitória, over five years. All patients were female with nodules in the scalp hair, 13 were of mixed race and ten were between two and six years old. The bot and humid climate of the region together with the patients' habits regarding use of conditioning creams favored the infection. Moistening the hair with water can facilitate visualization of the nodules.

Keywords: Mycoses; Piedra; Trichosporon.
\end{abstract}

\section{INTRODUÇÃO}

Piedra branca é infecção fúngica crônica da cutícula do pêlo, rara, descrita originalmente por Beigel em 1865. ${ }^{1}$ Tem como agente etiológico a levedura Trichosporon beigelii, mas a partir de estudos moleculares foram determinadas seis espécies de Trichosporon: T. ashii, T. asteroides, T. cutaneum (sinônimo de T. beigelii), T. mucoides, T. ovoides e T. inkin. As duas últimas espécies também estão envolvidas em casos de piedra branca, e as demais espécies são responsáveis por pneumonites, infecções mucosas, endocardites, ceratites, hepatites, peritonites, etc. ${ }^{2.5}$

A piedra branca tem distribuição universal, com predileção por regiões temperadas e tropicais. No Brasil é alta sua freqüência na Região Norte. Afeta indivíduos de ambos os sexos e pode comprometer qualquer faixa etária. ${ }^{1,4,6}$

\footnotetext{
Recebido em 16.06.2003.

Aprovado pelo Conselho Consultivo e aceito para publicação em 16.10.2003

* Trabalho realizado na Escola de Medicina da Santa Casa Dde Misericórdia de Vitória - Espírito Santo - EMESCAM

Professora-assistente do Serviço de Pós-Graduação em Dermatologia da Emescam e responsável pelo Laboratório de Micologia

Professor Titular do Serviço de Pós-Graduação em Dermatologia da Emescam

(C)2005 by Anais Brasileiros de Dermatologia
} 
O Trichosporon beigelii habita solo, água e vegetais, como também já foi encontrado em macacos, cavalos e fazendo parte da flora normal da pele (principalmente área inguinocrural) e mucosa oral, ${ }^{1,4}$ porém o meio de transmissão permanece desconhecido. Observa-se que a piedra branca não está relacionada à falta de higiene ou a baixo padrão socioeconômico e não tem transmissão sexual. ${ }^{1,4,5}$

Caracteriza-se clinicamente pela presença de nódulos moles, de coloração variando do branco ao castanho-claro, de diversas formas e tamanhos, assintomáticos, comprometendo a haste dos pêlos das áreas genitais, das axilas, barba e bigode, menos freqüentemente do couro cabeludo, podendo acometer cílios e sobrancelhas. ${ }^{6-11} \mathrm{O}$ folículo piloso não sofre alteração, mas a pele subjacente pode estar afetada com lesões eritêmato-escamosas, sem bordas nítidas, úmidas e pruriginosas. ${ }^{910} \mathrm{Na}$ região genital é observado sinergismo entre o Trichosporon beigelii e a bactéria Coryneform, participante da flora normal dessa região ${ }^{5,6} \mathrm{Em}$ pacientes imunodeprimidos o T. beigelii pode disseminar-se e produzir lesões cutâneas pustulosas, nodulares, purpúricas ou necróticas. ${ }^{6}$

Preconiza-se a diferenciação diagnóstica com piedra preta, que apresenta nódulo mais duro e aderente ao fio do cabelo, pediculose, tricomicose nodular axilar e anormalidades da haste do cabelo, como tricorrese nodosa e tricoptilose. ${ }^{5}$ Quando presente na área genital e comprometendo a pele subjacente, faz diagnóstico diferencial com dermatofitoses, candidíases e eritrasma. ${ }^{9-11}$

O diagnóstico laboratorial é feito por meio da análise dos pêlos afetados ao microscópio óptico, utilizando-se hidróxido de potássio a $20 \%$ em solução aquosa de dimetil-sulfóxido, onde são observados nódulos formados por elementos micelianos (artroconídeos e blastoconídeos, binômio que caracteriza o gênero Trichosporon $)^{9,10}$ dispostos perpendicularmente à superfície dos pêlos. Em meio de ágar Sabouraud sem actidiona à temperatura ambiente, após semeadura dos pêlos afetados, observa-se o crescimento moderado de colônia branco-amarelada, pregueada e com aparência de cera, posteriormente adquirindo coloração acinzentada. A micromorfologia da colônia mostra hifas hialinas, artroconídeos e blastoconídeos. ${ }^{3,12} \mathrm{O}$ gênero Trichosporon não fermenta carboidratos, mas assimila glicose, galactose, sacarose, maltose, trealose (provavelmente) e lactose, além de ser urease-positivo. ${ }^{3}$

A terapêutica de escolha da piedra branca é cortar o pêlo da área afetada, e, devido à recorrência freqüente, são indicados antifúngicos tópicos, como imidazólicos, ciclopirox olamina, piritionato de zinco, etc. ${ }^{1,4,6}$

\section{RELATO DOS CASOS}

Foi realizado estudo retrospectivo baseado em dados obtidos das fichas arquivadas de pacientes que se submeteram a exames para pesquisa de fungos no laboratório do Serviço de Dermatologia da Santa Casa de Misericórdia de Vitória, ES durante o período de primeiro de janeiro de 1998 a primeiro de janeiro de 2003. Das fichas com diagnóstico clínico de piedra branca foram anotados: nome, idade, sexo, raça, bairro e cidade de residência dos pacientes, a localização das lesões e os resultados dos exames micológico direto e cultura para fungos.

O exame micológico direto dos pêlos afetados retirados dos pacientes foi realizado com a aplicação de uma gota de hidróxido de potássio a $20 \%$ em solução aquosa de dimetil-sulfóxido sobre lâmina de microscopia, recoberta por lamínula, e a preparação observada ao microscópio óptico. Os pêlos afetados foram semeados em meio de ágar Sabouraud sem actidiona e observados diariamente durante 30 dias, para a avaliação macroscópica e microscópica da colônia.

Durante o período selecionado para o estudo foram atendidos no laboratório 3.350 pacientes para a pesquisa de fungos, advindos de diversos bairros da Grande Vitória, com média de 670 pacientes por ano, sendo $15(0,44 \%)$ com o diagnóstico clínico e confirmação laboratorial de piedra branca, em média três pacientes por ano.

Os 15 pacientes eram do sexo feminino e apresentavam clinicamente nódulos diminutos, em torno de um a dois milímetros de diâmetro, coloração branco-amarelada, aderidos à haste dos fios de cabelos do couro cabeludo (Figura 1), mais concentrados nas áreas frontoparietoccipitais, assintomáticos e sem alterações no folículo piloso e na pele subjacente. Nenhuma outra área do corpo apresentava lesão. Quanto à raça, 13 pacientes $(86,6 \%)$ eram pardas e duas $(13,4 \%)$ brancas; a faixa etária mais acometida foi a de dois a seis anos de idade (66,6\%), fase préescolar. O quadro 1 mostra a distribuição dos pacientes quanto à idade.

Os exames micológicos diretos dos fios de cabelos das 15 pacientes mostravam nódulos brancoamarelados, moles, aderidos à haste dos cabelos, sem contudo os alterar, formados por estruturas fúngicas que eram artroconídeos e blastoconídeos dispostos perpendicularmente aos fios, caracterizando o gênero Trichosporon spp (Figura 2).

As culturas em meio de ágar Sabouraud dos pêlos afetados das 15 pacientes mostravam macroscopicamente o crescimento de colônia leveduriforme, de cor amarelada, pregueada, com aparência de cera (Figura 3), e a micromorfologia das colônias utilizando-se o corante lactofenol-azul-algodão evidenciava hifas septadas, blastoconídeos e artroconídeos, carac- 


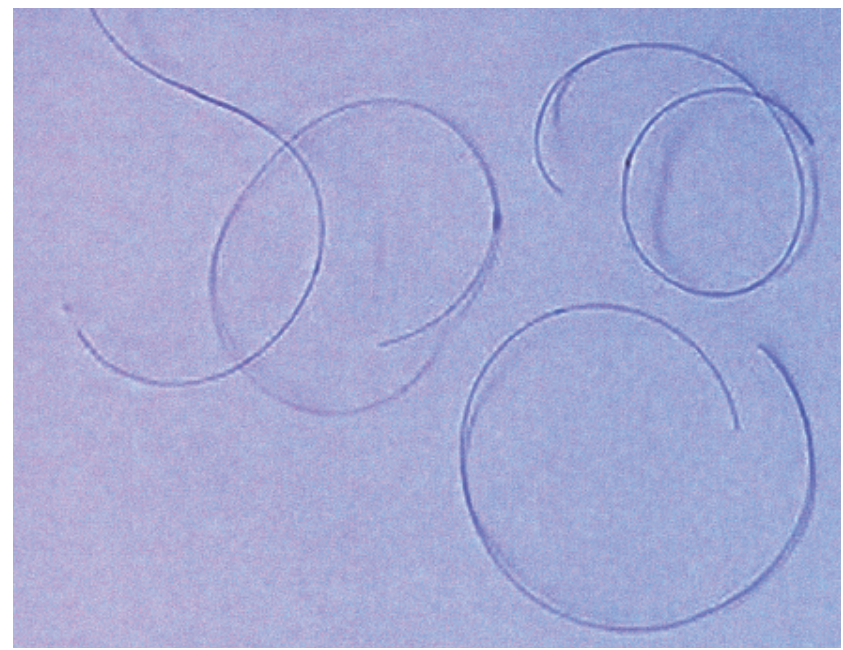

Figura 1: Fios de cabelos do couro cabeludo com diminutos nódulos de piedra branca aderidos à haste

terísticos do gênero Trichosporon spp (Figura 4). Devido à falta de recursos financeiros, não foram realizados estudos moleculares para a determinação das espécies fúngicas.

\section{DISCUSSÃO}

A piedra branca é infecção fúngica rara, com casos clínicos relatados na América do Sul, América do Norte, Sul da Ásia, Oriente Médio, Europa, Japão e Austrália. No Brasil há referência de casos na Paraíba, no Rio de Janeiro, em São Paulo, Belém e, a partir deste estudo, na Grande Vitória (Serra, Vitória, Vila Velha, Cariacica e Viana). A maioria dos casos brasileiros de piedra branca referem-se à localização em áreas genitais, e lesões nos pêlos do couro cabeludo são da Paraíba, de São Paulo e do Rio de Janeiro. ${ }^{5,911,13}$

Durante os cinco anos do estudo (1998 a 2002) a piedra representou $0,44 \%$ dos pacientes submetidos à pesquisa de fungos no laboratório do Serviço de Dermatologia da Santa Casa de Misericórdia de

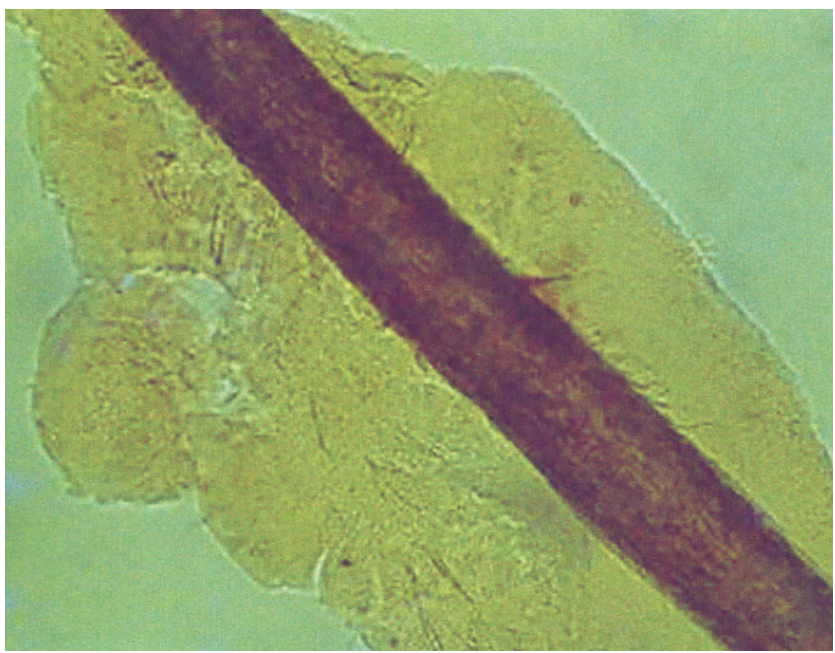

Figura 2: Exame micológico direto mostrando nódulo amarelado ao redor do fio de cabelo, formado por hifas e artrosporos

Vitória, refletindo sua ocorrência esporádica nessa população.

Os pacientes advinham de diversas regiões da Grande Vitória e tinham um padrão socioeconômico variável, entre baixo e médio, sem associação com falta de higiene pessoal, corroborando os dados estatísticos do estudo da Paraíba, que não evidenciou correlação entre esses fator e a doença. ${ }^{5}$

Todos os pacientes eram do sexo feminino e tinham os cabelos lanosos, de comprimento médio ou longo, o que justifica o hábito do uso de cremes recondicionadores em maior quantidade, permitindo a manutenção de umidade nos fios de cabelos, o que poderia contribuir com a infecção e a permanência dos fungos. A maioria das pacientes $(66,6 \%)$ encontrava-se na fase pré-escolar, entre dois e seis anos de idade, mas os responsáveis pelas crianças negavam casos semelhantes em alunos da mesma escola.

Havia sempre referência a tratamentos anteriores para pediculose do couro cabeludo, sem regressão

QUADro 1: Freqüência de pacientes acometidas por nódulos de piedra branca no couro cabeludo distribuídos por idade e número de casos.

\begin{tabular}{|ccc|}
\hline Idade & $N^{\circ}$ de casos & Porcentagem \\
\hline 2 anos & 2 & 13,4 \\
3 anos & 1 & 6,6 \\
4 anos & 4 & 27 \\
5 anos & 3 & 20 \\
7 anos & 1 & 6,6 \\
8 anos & 1 & 6,6 \\
9 anos & 1 & 6,6 \\
16 anos & 1 & 6,6 \\
43 anos & 1 & 6,6 \\
\hline Total & 15 & 100 \\
\hline
\end{tabular}




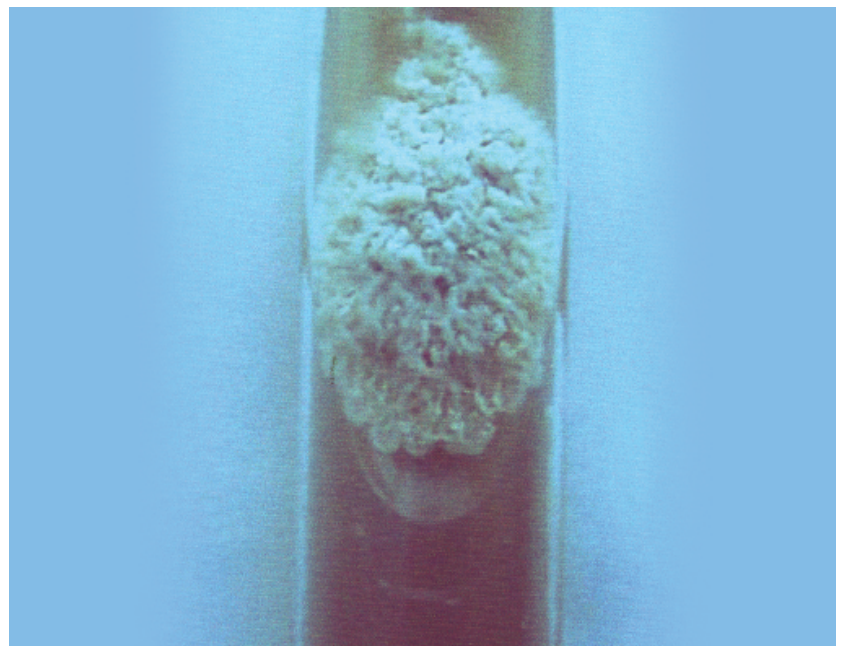

Figura 3: Cultura em meio de ágar Sabouraud - colônia leveduriforme, cor creme, pregueada, aparência de cera.

das lesões, levando as pacientes às consultas dermatológicas, como também, relatava-se a facilidade da visualização dos nódulos aderidos aos fios de cabelos após serem molhados com água corrente, fato verificado pelos autores durante o exame das pacientes.

A pele do couro cabeludo não estava afetada, nem foram observados casos familiares, e todas as pacientes ou seus responsáveis negavam banhos em águas paradas ou rios, afastando a hipótese de contaminação nesses locais. O clima da região da Grande Vitória é úmido e quente na maioria dos meses do ano,

\section{REFERÊNCIAS}

1. Zaitz C, Campbell I, Marques AS, Luiz LRB, Souza VM. Compêndio de micologia médica. Rio de Janeiro: MEDSI; 1998. p.72-4.

2. Lacaz CS, Porto E, Martins JEC, Heins-Vaccari EM, Melo NT. Tratado de Micologia Médica Lacaz. 9a ed. São Paulo: Sarvier; 2002. p. 631-3.

3. Lacaz CS, Porto E, Heins Vaccari EM, Melo NT. Guia para identificação: Fungos, Actinomicetos, Algas de interesse médico. São Paulo: Sarvier; 1998. p.138-9.

4. Talhari S, Neves RN. Dermatologia Tropical. Rio de Janeiro: MEDSI; 1995. p.122-3.

5. Pontes ZBVS, Ramos AL, Lima EO, Guerra MFL, Oliveira NMC, Santos JP. Clinical and Mycological Study of Scalp White Piedra in the State of Paraíba, Brazil. Mem Ins Oswaldo Cruz. 2002; 97: 747-50.

6. Guidelines of care for superficial mycotic infections of the skin: Piedra. J Am Acad Dermatol. 1996; 34: 122-4.

7. Sodré CT. Ceratofitoses. An Bras Dermatol. 1989; 64: 97-9.

8. Juang JM, Marques ERMC, Couto LWM, Metelmann U, Silva EH. Piedra Branca no couro cabeludo. An Bras Dermatol. 2000; $75: 25$.

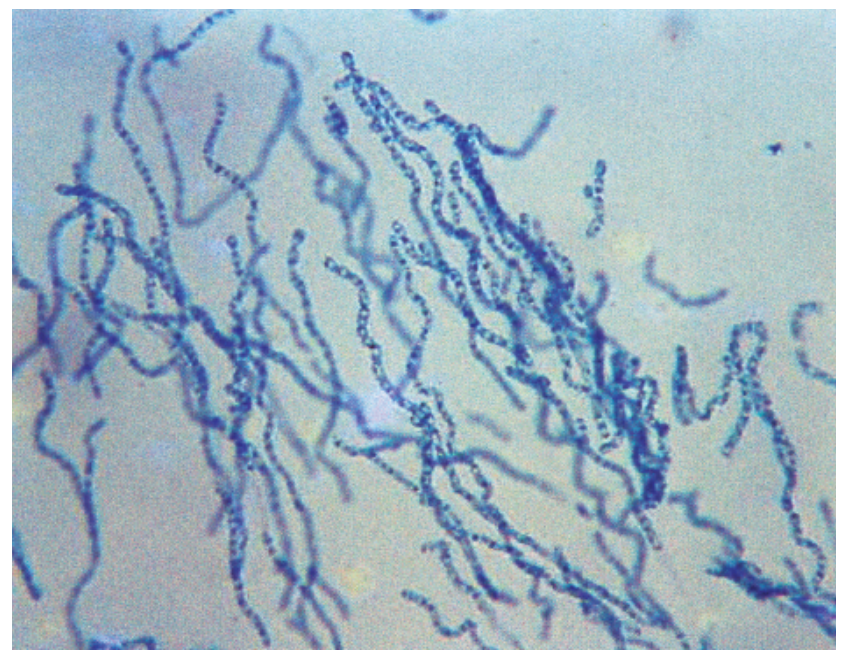

FIGURA 4: Micromorfologia da colônia - presença de blastosporos e artrosporos hialinos de Trichosporon $s p p$

o que deve favorecer a infecção pelo Trichosporon spp.

Durante os cinco anos incluídos no estudo não foram observados pacientes com nódulos de piedra preta, assim como não foi encontrada publicação referindo casos dessa doença no Estado do Espírito Santo.

As pacientes foram orientadas a cortar os cabelos e utilizar xampus à base de piritionato de zinco a $2 \%$ ou cetoconazol a $2 \%$ durante 30 dias, sendo observado ao final desse tempo regressão das lesões, e nenhuma delas retornou com o quadro clínico, demonstrando a ausência de recidiva.

9. Carneiro JA, Assis FA, Trindade Filho J, Carvalho CAQ. Piedra branca genital 40 casos. An Bras Dermatol. 1971; 46: 265-9.

10. Carneiro JÁ, Alonso AM, Araújo FA. Novos Casos de piedra branca genital (PBG). An Bras Dermatol. 1973; 48: 133-6.

11. Gondim-Gonçalves $\mathrm{H}$, Mapurunga ACP, Melo-Monteiro C, Lowy G, Lima AAB. Piedra Branca - revisão de litera tura a respeito de três casos. Rev Bras Med. 1991; 48 : 541- 7.

12. Lacaz CS, Porto E, Martins JEC. An Bras Dermatol. 1989; 64 (Supl.1): 55-91.

13. Brito AC, Costa CAA. "Piedra" em Belém do Pará. An Bras Dermatol. 1966; 41: 227-8.

\footnotetext{
ENDEREÇO PARA CORRESPONDÊNCIA: / MAILING ADDRESS: Lucia Martins Diniz

Rua Carlos Martins, 634 - Bairro Jardim Camburi Vitória ES CEP 29090-060

Tels.: (27) 3337-4236/3325-0940

E-mail:diniz@tecnosite.com.br
} 